\title{
DOES THE MICRO LAND SNAIL, KALIELLA BARRAKPORENSIS (MOLLUSCA: GASTROPODA), EXHIBIT PLANT PREFERENCE AND AGGREGATION? A FIELD-BASED ANALYSIS
}

\author{
Himangshu Barman ${ }^{1,2}$, GaUtam Aditya ${ }^{1, *}$ \\ ${ }^{1}$ Department of Zoology, University of Calcutta, 35 Ballygunge Circular Road, Kolkata 700019, \\ India \\ ${ }^{2}$ Department of Zoology, Ramnagar College, Depal, Purba Medinipur, West Bengal, India. \\ *Corresponding author: e-mail: gazoo@caluniv.ac.in; Telephone: +91-9432340175
}

\begin{abstract}
.
The spatial scale occurrence of the micro land snail Kaliella barrakporensis (L. Pfeiffer, 1852) in the host plants was assessed from selected sites of West Bengal, India. In course of a survey, the collection of K. barrakporensis from randomly selected plants was accomplished for the purpose of highlighting-(a) distribution in host plants, (b) variation in abundance in different height and (c) the dispersion pattern. Although the snails were observed in seven different plants, the presence was more prominent in the lemon plant (Citrus limon), with an average of about 24 individuals / 100 leaves. The logit based principal component regression indicated significant differences in the preference of the host plants with abundance in $\mathrm{C}$. limon followed by Hibiscus rosa-sinensis and Nyctanthes arbor-tristis, which was further substantiated through Kruskal Wallis test $(K=37.299 ; P<0.0001, d f=5)$. The heterogeneity in the distribution of $\mathrm{K}$. barrakporensis at different heights of the plant $\mathrm{C}$. limon was also observed with maximum abundance at about $90 \mathrm{~cm}$ height with least number of snails at the ground level $(K=39.012 ; P<0.0001 ; d f=6)$. On the basis of the variance to mean ratio $\left(s^{2} / m=1.847 \pm 0.16 \mathrm{SE}\right)$, negative binomial dispersion parameter $k(1.03 \pm 0.33 \mathrm{SE})$, Lloyd mean crowding (i) $(1.083 \pm 0.16 \mathrm{SE})$, and fit to the negative binomial distribution appared to comply with the aggregated dispersion in lemon plant. Apparently, the micro land snail K. barrakporensis was encountered in at least seven different host plants with estimated aggregated dispersion pattern in lemon plant. Further studies on the resource preferences of the micro snail $\mathrm{K}$. barrakporensis, should be evaluated to support conservation initiative and spread beyond native habitats.
\end{abstract}

Key words: micro land snail, Kaliella barrakporensis, Citrus limon, dispersion, host plant

\section{INTRODUCTION}

The terrestrial molluscs (Mollusca: Gastropoda) constitute one of the largest invertebrate group, with about 24000 valid species described so far (Lydeard et al. 2004; Rosenberg 2013). In parity with the taxonomic diversity, the snails and slugs exhibit huge extent of adaptation to the varied habitat conditions with multiple functional roles (Baur et al. 2014; Moreno-Rueda 2014). Almost all the available resources of the terrestrial ecosystems are exploited by the snails and slugs as food and shelter. As a result, the snails and slugs appear as dominant group in the terrestrial habitats (Astor et al. 2014, 2015; Nurinsiyah et al. 2016), often exhibiting great extent of species diversity in the assemblages (Astor et al. 2014, 2017; Schmera \& Baur 2014; Remm \& Lõhmus 2016). Commonly the snails and slugs are encountered in the litters, plant bark, rock crevices and garden wall reflecting the generalized pattern of exploitation of habitat elements (Tattersfield et al. 2001; Astor et al. 2015, 2017; Nurinsiyah et al. 2016). Some terrestrial snails, however, show restricted distribution and specificity for the woody plants and the trees as the habitat (Craig 1972; Heatwole and Heatwole 1978; Bledose and Minnick 1982; Raut \& Ghose 1984; Raheem et al. 2008), thereby qualifying as an arboreal species. Still, few species of terrestrial snails, termed as 'micromolluscs', owing to the smaller size $(<5 \mathrm{~mm}$ in shell dimension) (Aravind et al. 2008; Sasaki 2008; Durkan et al. 2013), are found in leaf litters as well as different plants.

The association with the host plant and the resource utilization of the arboreal snail have been widely explored for various species like Euhadra amaliae (Watada \& Wada 1996, 1998), Sitala jenynsi (Kasigwa 1999a, 1999b), Boninosuccinea ogasawarae and B. punctulispira (Sugiura 2011), Caracolus caracolla (Bloch and Stock, 2014), and Satsuma (Luchuhadra) eucosmia (Takeuchi \& Takeda 2016). In Indian context, the significance of the land snails is widely acknowledged (Aravind et al. 2008; Sen et al. 2012), the studies are focused mostly on the taxonomic documentation and species diversity of the arboreal and other land snails including the micromolluscs, 
mostly from the Western Ghats (Rao et al. 1984; Aravind et al. 2005, 2008; Raheem et al. 2014). In a recent survey, the micro land snail Kaliella barrakporensis (L. Pfeiffer, 1852) (Gastropoda: Chronidae) was encountered from the lemon orchards of selected regions of West Bengal, India, prompting us to initiate a study to register the distribution pattern of the snails. A primary estimate revealed that the endemic micro land snail, $K$. barrakporensis uses plants like, jasmine (Nyctanthes arbor-tristis), lemon (Citrus limon), jack fruit (Artocarpus heterophyllus), banana (Musa acuminata), china rose (Hibiscus rosa-sinensis), crape jasmine (Tabernaemontana divercata) and turmeric (Curcuma longa) as habitats. Using the relative abundance of the snail $K$. barrakporensis in the host plants, an estimate about the preference could be judged that may provide necessary information on the conservation planning, particularly when the land snail conservation is given priority (Aravind et al. 2008; Sen et al. 2012). In Indian context, particularly from West Bengal, the studies on the arboreal snails are limited to the succineid snail Indosuccenia semiserica and the snail Rhachis bengalensis are recorded from different places of West Bengal (Raut \& Ghose 1984; Raut \& Biswas 1991; Das \& Bhaumik 1998). In order to implement strategies for conservation of arboreal snails, the information on the host plant preferences is a pre-requisite to ensure appropriate resources for growth and fecundity of the target species. Considering the conservation effort in general (Sen et al. 2012) and understanding the spread in non-native area like UK (Preece \& Naggs 2014), information on the host plants exploited and the dispersion pattern of $K$. barrakporensis will therefore, be useful.

\section{Materials and Methods}

\subsection{Study sites}

The observation on the distribution of the snail $K$. barrakporensis was made considering Coochbehar $\left(26.3452^{\circ} \mathrm{N}, 89.4482^{\circ} \mathrm{E}\right)$, West Bengal, India, as the geographical area. Selected bushes in and around the home gardens were used as the study sites, which hosted diverse plant species, including lemon, crape jasmine and banana (Fig 1). The ground was cov-

Figure 1. A glimpse of the sites surveyed for the presence of the snail K. barrakporensis in Coochbehar, West Bengal, India. (a) lemon plant at the edge of agricultural field, (b), china-rose plant in a home garden (c) crepe jasmine plant in a home garden, (d) banana plant outside home garden, (e) lemon plant amidst coconut and areca nut trees near a bush, and (f) the snail K. barrakporensis, shell and living specimens.

(a)

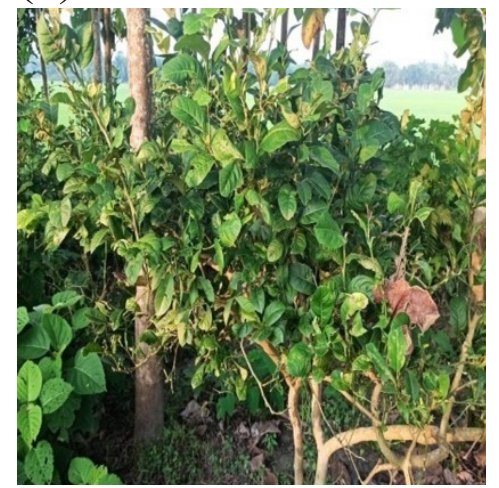

(d)

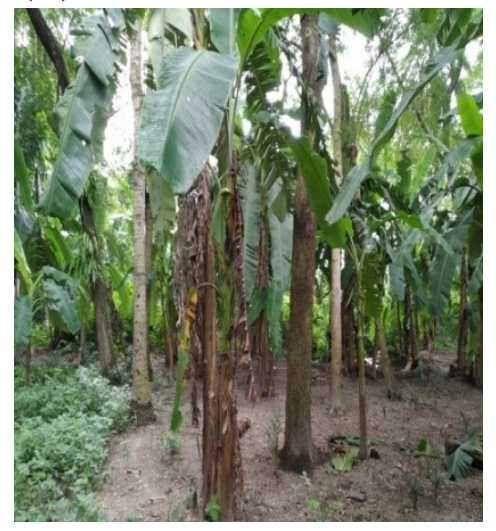

(b)

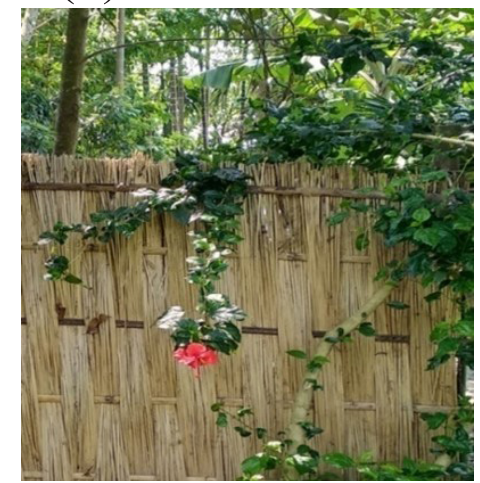

(e)

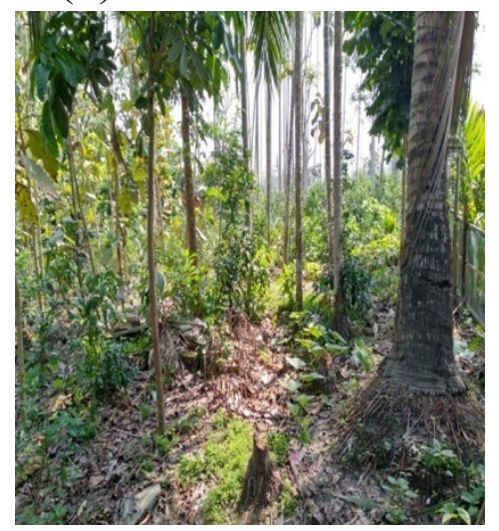

(c)

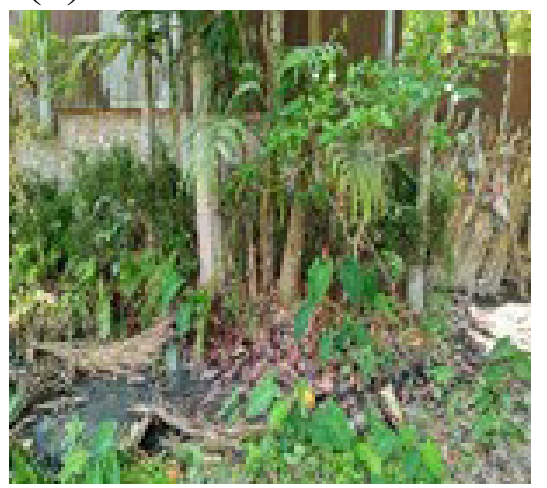

(f)
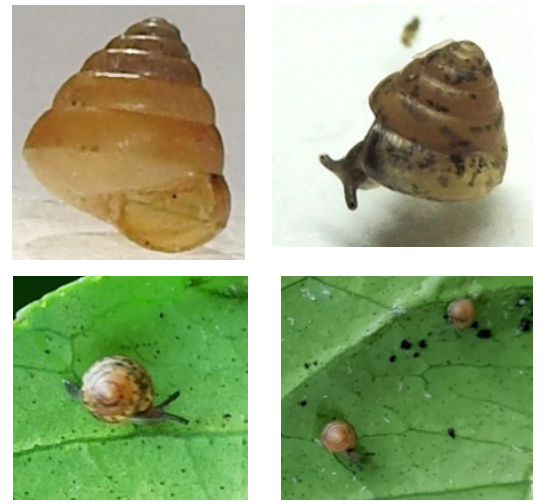
ered with detritus in most instances with bare soil and patches of grasses prominently forming a mosaic pattern. In few cases, the bushes and gardens were located adjacent to the agricultural field while, in others, the gardens were near human settlements and banana plantations. The study sites were far from the metallic roads and qualified more as rural and suburban areas. At least nine different sites were selected for the observation of distribution of the snails and from each site, random collection of the snails was made from the host plants. Observations were continued for more than 20 different dates during July to November of 2015 and 2016 coinciding with the monsoon period, when the probability of the encounter of the snails was high (Rao 1925; Raut \& Ghose 1984; Mitra et al. 2004). The observations and snail collections were made at early morning (6:00 AM - 8:00 AM) and evening hours (17:00 PM - 19:00 $\mathrm{PM})$ in the sampling days. Selected snail specimens $(\mathrm{n}=50)$ were brought to the laboratory for confirmation of the identification and record of the shell height ( $\mathrm{SH}$, in $\mathrm{mm}$ ) and body weight (BW, in $\mathrm{mg}$ ). The shell height of $K$. barrakporensis was initially measured under microscope using ocular micrometer (Erma, Japan) and later transformed into nearest $0.1 \mathrm{~mm}$ while the body weight was measured in a pan balance (Afcoset, India) to the nearest $0.1 \mathrm{mg}$. In the laboratory the snails were maintained in the plastic container with water dipped tissue paper at the inner base for moist condition inside the container, for height and weight measurements.

\subsection{Observation on snail dispersion and distribution}

Although the mention of the micro land snail $K$. barrakporensis appears in recent literature (Raheem et al. 2014), little information is available on the biology and ecology in Indian context (Mitra et al. 2004). Apparently, the snails appear near human settlements in the home gardens, damp walls and cultivated areas (Mitra et al. 2004). The shell of K. barrakporensis is conical and narrowly perforate with oblique sculpture and six whorls (Blanford \& Godwin-Austen 1908) with less than $4 \mathrm{~mm}$ in shell height and diameter (Mitra et al. 2004). In the present instance, the selection of the plants and the study sites were made following encounters of the snail during preliminary observations on the malacofauna of the concerned geographical area. Thus, in the selected sites, the study on the distribution of K. barrakporensis in host plant was performed in twenty-three (23) lemon plant (C. limon), seven (7) jack fruit plant ( $A$. heterophyllus), nine (9) jasmine plant ( $N$. arbor-tristis), eleven (11) china rose plant (H. rosa-sinensis), fifteen (15) banana plant (M. acuminata), seven (7) crape jasmine plant ( $T$. divercata) and two (2) turmeric plant $(C$. longa) spread across the different regions of Coochbehar, West Bengal, India. During the survey, frequency and position of the snail in each plant (leaf, bark, stem, and / branch) were recorded. The snails remained almost inconspicuous remaining inside the barks of stems and branches, but noticeable in the leaves and axils of the plants. Data on the relative abundance of $K$. barrakporensis in all the plants were collected following observations from at least 100 leaves through all branches, except for banana plant, where all the leaves were considered. In all instances, the abundance of the snails in each plant was recorded for further analysis, along with the geographical co-ordinates of the surveyed sites.

On the basis of the preliminary observation, the leaf of lemon plant was found to be preferred by $K$. barrakporensis as a suitable microhabitat. As a consequence, the dispersion pattern (Ludwig \& Reynolds 1988; Krebs 1999) of the snail in the lemon plant was assessed. The data on the relative abundance of the snail in lemon plant was recorded from 100 randomly selected leaves from bottom, middle and top region of each plant surveyed. Here, the number of random sample $\left(\mathrm{n}_{\mathrm{s}}\right)$ was 23 (plants) and the number of units $\left(\mathrm{n}_{\mathrm{u}}\right)$ was 100 (leaves) in each sample (Solen $\&$ Croft 1998), with each plant being less than 2.5 $\mathrm{m}$ and two plants being separated with a minimum of $500 \mathrm{~m}$ distance. The frequencies of the snail in each leaf were categorized into five classes, zero (0), one (1), two (2), three (3) and greater than or equal to four $(\geq 4)$, so as to assess for the dispersion pattern according to negative binomial distribution (Ludwig \& Reynolds 1988; Krebs 1999). The observed frequency for each class was recorded and formed the basis for the estimation of the expected frequency following the negative binomial distribution (Bliss \& Fisher 1953; White \& Bennetts 1996; Krebs 1999) (Table 1).

An assessment on the vertical distribution of the $K$. barrakporensis in the host plant was made during the same time period, through a separate survey on 20 randomly selected lemon plants from the same geographical region. In each lemon plant, the number of snails encountered at a particular height was recorded. After marking the plants using a scale, at a gap of $30 \mathrm{~cm}$, ranging from 0 to $180 \mathrm{~cm}$ plant height, 
the relative abundance of the snails (collected from the leaves, axils, stems or branches) at each height was recorded, to evaluate whether there exists any difference in the choice of height by the snail $K$. barrakporensis.

\subsection{Data analysis}

The data on the relative abundance of the snails at different sites were tested for compliance with the normality (Shapiro-Wilk test) (Zar 1999). A logit based principal component regression (PCR) was made to justify the distribution pattern of the snail as a function of the host plants (Aguilera \& Escabais 2000). In case of the PCR regression, the logistic regression is calculated on the basis extracted principal components which correspond to the explanatory variables in the equation. In this logistic regression, the response variable, relative density of $K$. barrakporensis is assumed to follow binomial (n, $\mathrm{p}$ ) distribution with $\mathrm{n}$ replicates (number of leaves in the plants) for each combination of the explanatory variables. Here, the probability parameter $\mathrm{p}$ represents the linear combination of explanatory variables. A logit link was used and the parameters of the model were estimated through maximum likelihood using the software XLSTAT (Addinsoft 2010), and against each of the parameters a Wald's $\chi^{2}$ value was used to judge the level of significance (McCullagh \& Nelder 1989; Fox 2008). A binomial generalized linear model with logit link was also applied using similar formula of the logistic regression, to justify the differences in the relative abundance of the snails at different plant height using 0 as the ground height and $180 \mathrm{~cm}$. The plant height was used as an explanatory variable while the relative abundance as the response variable. In addition, the count data on the relative abundance of the snail in different host plant was also subjected to nonparametric Kruskal-Wallis test with Steel-Dwas-Critchlow-Fligner multiple comparison to justify the differences in the distribu-

Table 1: Synoptic list of the equations used in the assessment of the dispersion and distribution of the snail K. barrakporensis observed in West Bengal, India. The dispersion parameters were measured on data on the snails in the 100 randomly selected leaves from each of the 23 lemon plants in the study sites.

\begin{tabular}{|c|c|c|c|}
\hline & Equation & Symbols & Estimation \\
\hline $\begin{array}{l}\text { Taylor's power } \\
\text { law }\end{array}$ & $\log \left(s^{2}\right)=\log \mathrm{a}+\mathrm{b} \log m$ & $\begin{array}{l}\text { where } s^{2} \text { is variance and } m \text { is } \\
\text { the mean value of the sample }\end{array}$ & $\begin{array}{l}\text { The value of } b \text { indicates extent } \\
\text { of aggregation of the snail in } \\
\text { the sample and was tested for } \\
\text { significance using t-test. }\end{array}$ \\
\hline $\begin{array}{l}\text { Lloyd's mean } \\
\text { crowding }\end{array}$ & $\dot{\mathrm{m}}=m+\frac{m}{k}$ & $\begin{array}{l}\text { where } \dot{m} \text { is the mean } \\
\text { crowding, } m \text { is the sample } \\
\text { mean and } k \text { is the dispersion } \\
\text { parameter }\end{array}$ & $\begin{array}{l}\text { The extent of 'patchiness' } \\
\text { expressed as } \dot{m} / m \text {, and judged } \\
\text { significance using a t-test }\end{array}$ \\
\hline $\begin{array}{l}\text { Negative } \\
\text { binomial } \\
\text { distribution } \\
(\mathrm{NBD}) \text { and } \\
\text { dispersion } \\
\text { parameter }\end{array}$ & $\begin{array}{l}p_{0}=\left(1+\frac{m}{k}\right)^{-k} \\
p_{r}=p_{0}\left(\frac{k+r-1}{r}\right)\left(\frac{m}{m+k}\right)^{r}\end{array}$ & $\begin{array}{l}\text { where } p_{0} \text { is the expected } \\
\text { frequency of zero }(0) \text { of the } \\
\text { studied snail in host plant } \\
\text { leaf; and, where } p_{r} \text { is the } \\
\text { chance of expected frequency } \\
\text { of any positive count } r \text {; the } \\
\text { dispersion parameter is } k\end{array}$ & $\begin{array}{l}\text { The expected frequencies of } \\
\text { the snails in the leaf samples to } \\
\text { estimate the compliance with the } \\
\text { NBD, using the log-likelihood G } \\
\text { test. }\end{array}$ \\
\hline $\begin{array}{l}\text { Binomial } \\
\text { generalized } \\
\text { linear model } \\
\text { with logit link }\end{array}$ & $\begin{array}{l}(\mathrm{y})=1 /\left(1+\exp \left(-\left(\mathrm{a}+\mathrm{b}_{\mathrm{i}} \mathrm{x}_{\mathrm{i}}+\ldots .+\right.\right.\right. \\
\left.\left.\left.\mathrm{b}_{\mathrm{n}} \mathrm{x}_{\mathrm{n}}\right)\right)\right), \\
\text { the logit link being } \\
\log _{\mathrm{e}}\left(\mu_{\mathrm{i}} /\left(1-\mu_{\mathrm{i}}\right)\right) \text { and the inverse } \\
\text { function is } \\
1 /\left(1+\mathrm{e}^{(-\eta i)}\right)\end{array}$ & $\begin{array}{l}\text { where } \mathrm{x} \text { represents the } \\
\text { explanatory variable (i to } \mathrm{n} \\
\text { numbers ) y represents the } \\
\text { relative density of the snails } \\
\text { species. } \mu_{i} \text { is the expected } \\
\text { value of the response; } \eta_{i} \text { is the } \\
\text { linear predictor; }\end{array}$ & $\begin{array}{l}\text { The distribution of the snails } \\
\text { [binary (sum) proportion] at } \\
\text { different height of the lemon plants } \\
\text { and the distribution of the snails in } \\
\text { different plants using logit based } \\
\text { principal component analysis; } \\
\text { Wald's chi-square was used to } \\
\text { judge the significance of the } \\
\text { parameters. }\end{array}$ \\
\hline
\end{tabular}


tion if any, among the host plants. Similar statistical test was also applied to justify the differences in the relative abundance at different height of the lemon plants. The tests were carried out in XLSTAT software (Addinsoft 2010).

The estimation of mean $(m)$, variance $\left(s^{2}\right)$ (Taylor 1961) mean crowding $(\dot{m})$ (Lloyd 1967) and dispersion parameter $(k)$ (Anscombe 1949; Bliss \& Fisher 1953; White \& Bennetts 1996) from snail abundance in the samples of 100 leaves from 23 lemon plants. Apart from the regression between variance and mean value of snail (Ludwig \& Reynolds 1988; Krebs 1999), the patchiness index $(\dot{m} / m)$ was estimated (Lloyd 1967). A significantly greater value from unity was justified using a t-test (Zar 1999) to indicate the dispersion pattern as aggregated or not. A significantly greater than 0 value of the inverse of dispersion parameter (1/k) (Bliss \& Fisher 1953) was also justified using a t-test on the same data. The negative binomial distribution model (NDM) was followed to know the distribution of the snail in lemon plant leaf on the magnitude of mean and variance values (Bliss \& Fisher 1953; White \& Bennetts 1996; Zhang et al. 2008). The compliance of the snail aggregation with the negative binomial distribution was judged using a Pearson's $\chi^{2}$ test (Bliss \& Fisher $1953)$ for the 23 samples separately (Table 1 ).

\section{RESULTS}

The individuals of the snail $K$. barrakporensis were observed moving, resting or mucus attached onto leaves, branches and stems of different host plants. In majority instances, when present in the stems and branches of the host plants, the snails remained inside the small crevices created by the barks. A total of $793 \mathrm{~K}$. barrakporensis of varied size groups were encountered from the study sites in different geographical coordinates (Fig 2) from 71 host plants with a mean of $11.17 \pm 1.97 \mathrm{SE}$ (range 1 to 97 individuals in each plant). A significant deviation from normality was observed (Shapiro-Wilk test, D $=0.558 ; \mathrm{P}<0.0001$; for data on snails in 71 host plants), a reflection of differences in snail abundance in the host plants in the sites. The shell height (in mm) of the collected $K$. barrakporensis was, mean, $3.14 \pm$ $0.04 \mathrm{SE}$ (range $2.1-4.1 \mathrm{~mm}$ ) and the body weight (in $\mathrm{mg}$ ) was 8.46 mean \pm 0.27 (range 3.9 to $14.2 \mathrm{mg}$ ) appearing similar to those observed elsewhere (Mitra et al. 2004). The relative abundance of K. barrakporensis varied in the 7 different host plants, namely, jasmine (Nyctanthes arbor-tristis), lemon (Citrus li-

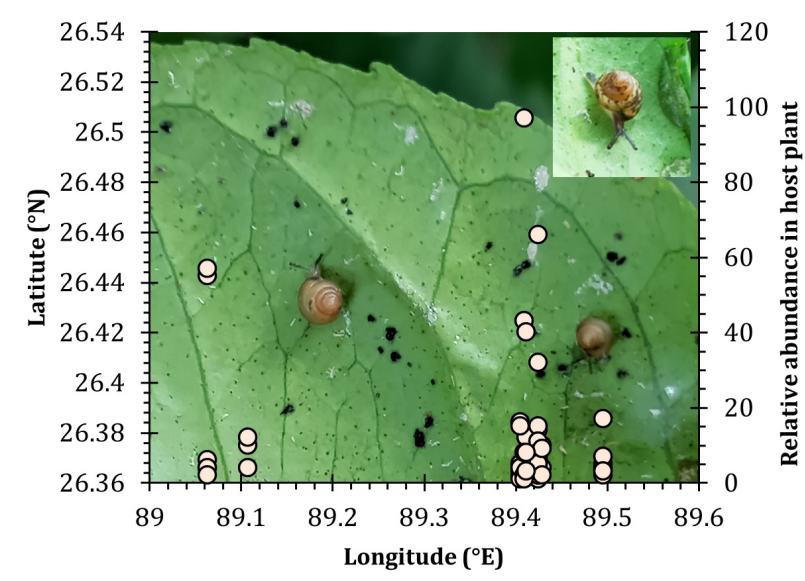

Figure 2: The distribution of the snail $K$. barrakporensis in the host plants sampled from different sites. The sites are shown in terms of the latitude and longitude.

mon), jack fruit (Artocarpus heterophyllus), banana (Musa acuminata), china rose (Hibiscus rosa-sinensis), crape jasmine (Tabernaemontana divercata) and turmeric (Curcuma longa) (Table 2). Application of the logit based principal component regression (PCR) yielded logistic regression with significant values for the parameters of the model, justifying that the relative abundance of $K$. barrakporensis in the seven plants was significantly different (Table 3 a). The ordination of the plants in the biplot (Fig 3) indicated considerable differences in terms of the relative abundance of the snail K. barrakporensis in the respective plants. Among five shrubs (crape jasmine, TDI; banana, MAC; jasmine, NAT; lemon, CLI and China rose, HRO) the lemon plant (CLI) and the China rose plant (HRO) occupied single coordinate sep-

Table 2: The relative abundance (mean $\pm \mathrm{SE}$ ) of $K$. barrakporensis in different host plant surveyed in Coochbehar, West Bengal, India. The result of Kruskal-Wallis non-parametric ANOVA followed by Steel-Dwass-Critchlow-Fligner procedure multiple comparisons exhibited significant difference at $\mathrm{P}<0.05$ level between selected plant pairs (sharing same alphabet).

\begin{tabular}{lll} 
Scientific name of host plant & Acronym & Mean $\pm \mathrm{SE}$ \\
\hline Nyctanthes arbor-tristis & NAT & $6.22 \pm 0.95^{\mathrm{d}}$ \\
Citrus limon & CLI & $23.56 \pm 5.17^{\mathrm{a}, \mathrm{b}}$, \\
Artocarpus heterophyllus & AHE & $2.71 \pm 0.60^{\mathrm{b}, \mathrm{c}}$ \\
Musa acuminata & MAC & $2.53 \pm 0.35^{\mathrm{a}, \mathrm{d}, \mathrm{e}}$ \\
Hibiscus rosa-sinensis & HRO & $8.63 \pm 0.93^{\mathrm{c},}$ \\
Tabernaemontana divericata & TDI & $5.71 \pm 1.79$ \\
Curcuma longa & CLO & $0.11 \pm 0.08$ \\
\hline
\end{tabular}




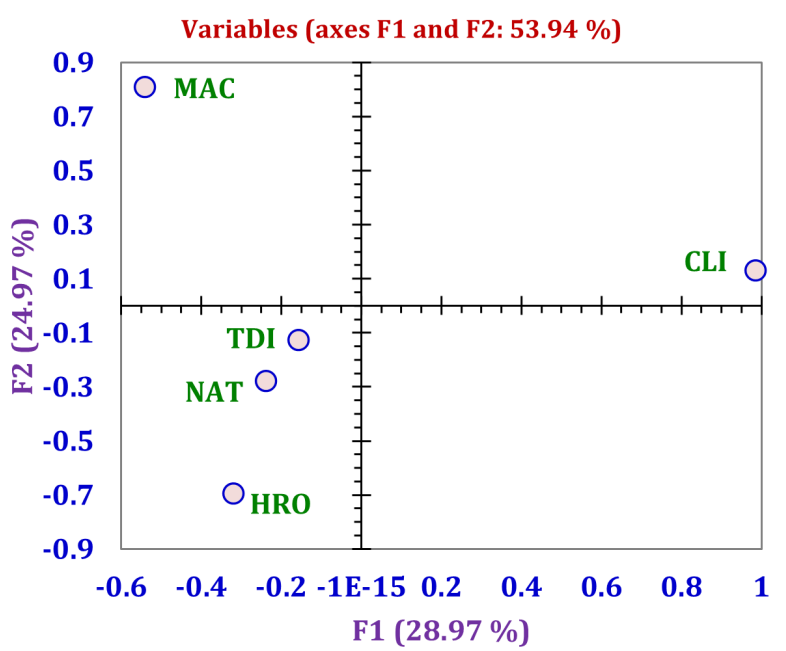

Figure 3: The biplot of the logit based principal component regression (PCR) to justify the dispersion pattern of the snail as a function of the host plant. In the biplot shown here, the orientation of the shrubs are provided in terms of the relative density of the snails observed in these shrubs in course of the sampling for the snails. HRO $-H$. rosa -sinensis, CLI - C. limon, TDI - T. divericata, NAT - N. arbor-tristis and $\mathrm{MAC}-$ M. acuminata

arately and crape jasmine (TDI), banana (MAC) and jasmine (NAT) plants occupied a single coordinate in the PCA analysis plot (axes F1 and F2 : 53.94\%)(Fig $3)$. The eigen values, variations explained by the extracted factors and the factor loadings and are shown in Table $3 b$. The variations in the relative abundance of the snail in observed host plants is significant in one-way Kruskal-Wallis test on the basis of mean data $(\mathrm{W}=37.299 ; \mathrm{df}=5, \mathrm{P}<0.0001)$. The post hoc multiple comparisons by Steel-Dwass-CritchlowFligner procedure revealed significant differences with reference to lemon plants against banana, jasmine and crape jasmine, which can be considered as an indicator of host plant preference by $K$. barrakporensis.

Extending the observations on the height wise distribution of the snail in a selected $20 \mathrm{C}$. limon plants, the difference was obvious when compared between different heights of the plant (Fig 4). In terms of the number of snails in each height mark, maximum numbers were observed at a height of $90 \mathrm{~cm}$ (or 3 feet height of the plant) while least number was observed at the ground level. Such variations appeared significant $(\mathrm{P}<0.05)$ in the results of the binomial generalized linear model with logit link (Table $3 \mathrm{c}$ ). In addition, the height wise distribution of the snails was found to be significant through Kruskal-Wallis test followed by multiple comparisons by
Steel-Dwass-Critchlow-Fligner procedure (Fig 4), with highest density in the $90 \mathrm{~cm}$ and least abundant at the ground level.

The dispersion of the snails in the lemon plant included observations of 542 snails in 2300 leaves of twenty-three different lemon plants $(100 * 23$ plants $)$ surveyed in the study sites. On the basis of this observation, the estimated mean, variance and dispersal parameter (variance to mean ratio, $s^{2} / m$ ), negative binomial factor $k$ (dispersion parameter), and mean crowding $(\dot{m})$ were assessed (Table 4$)$ to highlight the extent of dispersion. In 18 out of 23 observations, the variance to mean ratio was greater than unity $\left(s^{2} / m>1\right)$, indicating clumped distribution pattern of $K$. barrakporensis in the lemon plant. On the whole, the $s^{2} / m$ values remained significantly greater than 1 , revealed through a two-tailed t-test, $\mathrm{t}_{(2), 22}=5.237$; $\mathrm{P}<0.0001)$. In the form of the Taylor's power law, the mean and variance of the data on the dispersion of $K$. barrakporensis could be represented as: $\log$ $s^{2}=0.262+1.04 \log m$, (intercept, $\log \mathrm{a}=0.262 \pm$ 0.09 SE; $\mathrm{t}_{(2), 21}=2.963$; and the slope, $\mathrm{b}=1.04 \pm$ 0.09 SE; $\mathrm{t}_{(2), 21}=11.212$; both being significantly different from 0 at $\mathrm{P}<0.0001$ level). However, $\mathrm{b}$ was not significantly greater than $1\left(\mathrm{t}_{(2), 21}=0.444\right.$; NS). The patchiness index $(\dot{m} / m)$ (range, 0.192 and 24.87 with mean $7.84 \pm 1.67 \mathrm{SE}$ ), and the inverse of dispersion parameter, $(1 / k)$ (range, 0.14 and 23.7 with mean $7.12 \pm 1.62 \mathrm{SE}$ were both significantly different from unity (for $\dot{m} / m ; \mathrm{t}_{(2) .22}=4.097 ; \mathrm{P}=0.0004$; for $1 / k$ values, $\left.\mathrm{t}_{(2), 22}=4.405 ; \mathrm{P}<0.0001\right)$. The values suggested trend toward clumped distribution, which was further shown through the distribution pattern of

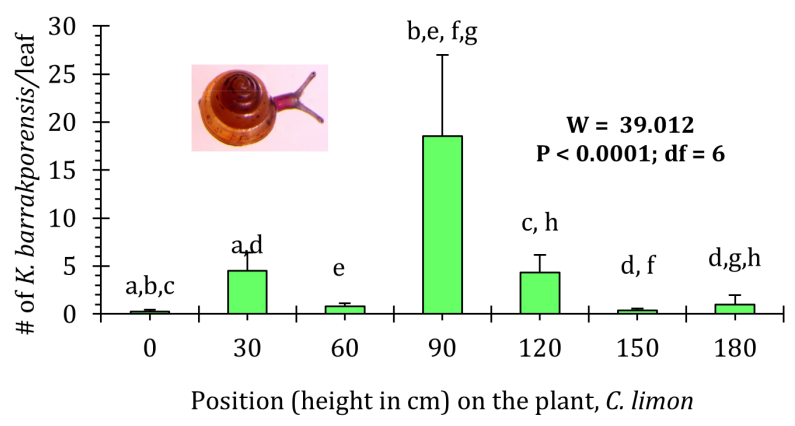

Figure 4: The relative abundance of the snail K. barakporensis observed on a randomly selected $20 \mathrm{C}$. limon plants in the study area. The difference in the height wise distribution of the snails was found to be significantly different. The result of the Kruskal-Wallis test (W) is shown with the bars sharing same alphabet are significantly different from one another at $\mathrm{P}<0.05$ level based on Steel-DwassCritchlow-Fligner procedure 
Table 3: The results of the principal component regression to justify the differences in the relative abundance of $K$.. barrakporensis in the different plants. In (a), the logistic regression equation and the significance levels of the parameters of the model are shown, while, in (b), the eigenvalues, variability explained and cumulative variability explained by the four extracted factors along with the factor loadings [the highest value against concerned factors is shown in bold] for the respective plants are shown. In (c), the results of the binomial generalized linear model based logistic regression on the distribution of $K$ barrakporensis in different height of the lemon plant $(\mathrm{n}=20)$ are shown. Here, $\mathrm{HRO}-H$. rosa-sinensis, CLI - C. limon, TDI - T. divericata, NAT - N. arbor-tristis and MAC - M. acuminata F1 through F4 - extracted factor of the PCR equation.

(a) The PCR based regression equation was:

No. of $K$. barrakporensis $(\mathrm{y})=1 /(1+\exp (-(-4.43+0.65 * \mathrm{~F} 1)))$,

Where, intercept $=-4.43 \pm 0.05$; Wald's $\chi^{2}=8002.072 ; \mathrm{P}<0.00001$;

for the factor $\mathrm{F} 1=-0.65 \pm 0.06$; Wald's $\chi^{2}=122.273 ; \mathrm{P}<0.0001$ ).

With incorporation of the input variables, the equation could be also be discerned as :

No. of $K$. barrakporensis $(\mathrm{y})=-4.52-0.37 *$ Plant-NAT + $1.1 *$ Plant-CLI - $0.45 *$ Plant-HRO - 0.29*Plant-TDI - 0.7*PlantMAC;

Where, NAT $=-0.128 \pm 0.051 ;$ Wald's $\chi^{2}=6.302 ; \mathrm{P}=0.012$;

$\mathrm{CLI}=0.531 \pm 0.05 ;$ Wald's $\chi^{2}=114.668 \mathrm{P}<0.0001$

$\mathrm{HRO}=-0.172 \pm 0.03 ;$ Wald's $\chi^{2}=33.088 ; \mathrm{P}<0.0001$;

TDI $=-0.084 \pm 0.013$; Wald's $\chi^{2}=41.931 ; \mathrm{P}<0.0001$;

$\mathrm{MAC}=-0.291 \pm 0.024 ;$ Wald's $\chi^{2}=143.735 ; \mathrm{P}<0.0001$.

(b)

\begin{tabular}{|c|c|c|c|c|}
\hline & F1 & F2 & F3 & F4 \\
\hline Eigenvalue & 1.449 & 1.249 & 1.184 & 1.119 \\
\hline Variability (\%) & 28.970 & 24.973 & 23.680 & 22.377 \\
\hline Cumulative \% & 28.970 & 53.943 & 77.623 & 100.000 \\
\hline \multicolumn{5}{|c|}{ Factor loadings } \\
\hline & F1 & F2 & F3 & F4 \\
\hline NAT & -0.238 & -0.279 & 0.863 & -0.346 \\
\hline CLI & 0.987 & 0.130 & -0.071 & -0.067 \\
\hline HRO & -0.319 & -0.695 & -0.612 & -0.201 \\
\hline TDI & -0.156 & -0.127 & 0.151 & 0.968 \\
\hline MAC & -0.540 & 0.809 & -0.192 & -0.130 \\
\hline
\end{tabular}

(c) Results of the height wise distribution of the snail $K$.barrakporensis in lemon plants $(\mathrm{N}=20)$

$(\mathrm{y})=1 /(1+\exp (-(-0.66-0.32 * \mathrm{x})))$,

where $\mathrm{y}=$ abundance of the snail and $\mathrm{x}=$ plant height.

The parameters of the model remained significant at $\mathrm{P}<0.05$ level

for intercept: $-0.66 \pm 0.09$; Wald's $\chi^{2}=53.906 ; \mathrm{P}<0.0001$;

for plant height: $-0.32 \pm 0.03$; Wald's $\chi^{2}=169.991 ; \mathrm{P}<0.0001$

Table 4: Dispersion, aggregation and patchiness parameters in 23 samples (Lemon tree, C. limon) of the snail K. barrakporensis. The values of the patchiness index $(\dot{m} / m)$, dispersion parameter $(k)$ and variance/mean ratio $\left(s^{2} / m\right)$ were significantly $(\mathrm{P}<0.001)$ greater than 1 supported by the t-test at $\mathrm{df}=22$.

\begin{tabular}{llll}
\hline$m$ & $s^{2}$ & $k$ & $s^{2} / m$ \\
\hline $0.02-0.970$ & $0.0198-1.908$ & $0.0419-6.965$ & $0.789-3.3331 .847 \pm 0.161$ \\
$0.236 \pm 0.052$ & $0.413 \pm 0.092$ & $1.034 \pm 0.325$ & \\
\hline$\dot{m}$ & $\dot{m} / m$ & $\dot{m}+1$ & $(\dot{m}+1) / m$ \\
\hline $0.010-2.4331 .083 \pm 0.163$ & $0.192-24.871$ & $1.010-3.433$ & $2.384-50.495$ \\
& $7.842 \pm 1.670$ & $2.083 \pm 0.163$ & $19.022 \pm 2.827$
\end{tabular}




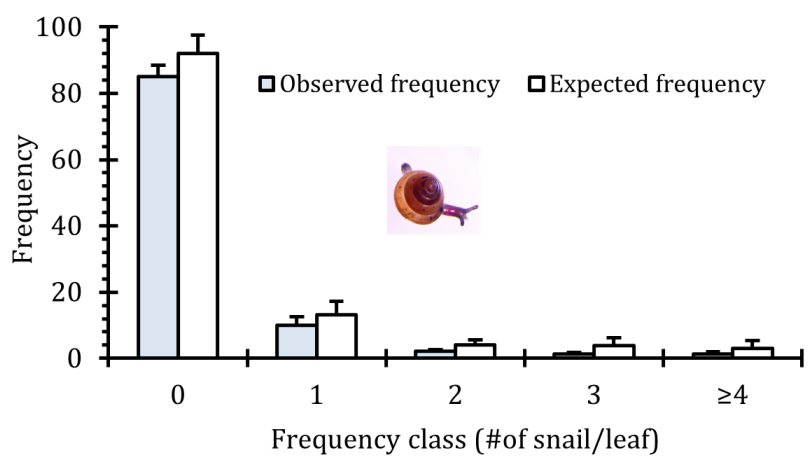

Figure 5: Expected and observed frequencies for the negative binomial distribution model of the presence of $K$. barrakporensis on the leave of lemon plant. The observations complied with NBD as per the Pearson's $\chi^{2}$-test for 20 out of 23 data sets from the lemon plant.

the snail in accordance with the negative binomial distribution pattern. As shown in the plot (Fig 5), the expected frequency of the snail in all five categories $(0,1,2,3, \geq 4$ number of snails per leaf) was not different than the observed frequency (Fig 5). However, except for two instances, all the values of Pearson's $\chi^{2}$ test remained not significant $(\mathrm{P}>0.05)$ indicating the expected and the observed frequencies fitted with the negative binomial model in majority of the data sets. Thus, it was apparent that the dispersion pattern of $K$. barrakporensis in the lemon plants appears to be clumped or significantly aggregated as indicated by the various indices of dispersion and the negative binomial factor.

\section{Discussion}

The distribution of the snail $K$. barrakporensis varied with the host plant species significantly, in all the sites surveyed in the present study. Among the different plants, $K$. barrakporensis was encountered at a higher number in lemon plants (C. limon) followed by china rose (H. rosa-sinensis) and jasmine (N. arbor-tristis). Although observed mostly from the leaves, in few instances, individuals of $K$. barrakporensis were observed to graze more on the branches and the trunk than on the leaves. When found in the leaves of the plant, the snail individuals remained adhered to the underside, perhaps as an adaptation against desiccation. Such orientations appear to be similar to the snails Euhadra amaliae observed in a small woodland garden (Watada \& Wada 1996). Desiccation is a concern for the arboreal land snails, particularly those that are distributed it the forest canopy and individual trees. An alternative space preferred by $K$. barrakporensis to avoid desiccation is the un- der spaces of the barks or between the leaf axils. In banana plant, the leaf sheath and the pseudostems are preferred by the K. barrakporensis, while for jackfruit tree, the under spaces formed by minute fissures and crevices in the barks were utilized. In few instances, the snails were observed in moist and dense leaf litters along with Allopeas gracile and Succinea baconi. While in the surveyed study sites, dense and moist leaf litter was not abundant, the exploitation of such habitats may not be unusual for K. barrakporensis in case of scarcity of the preferred plants. Such possibilities require to be judged further to justify the extent of resource exploitation of the micro land snail, K. barrakporensis. Abundance of the arboreal snails varies with the plant types and the resources available within the plants, as evident from the studies on the snails like Carocolus spp. and Polydontes spp. (Heatwole \& Heatwole 1978), E. amaliae (Watada \& Wada 1996, 1998), S. jenynsi (Kasigwa 1999a, 1999b), $B$. ogasawarae and B. punctulispira (Sugiura 2011), C. caracolla (Bloch \& Stock 2014), and S. (L.) eucosmia (Takeuchi and Takeda 2016). In case of the snails in the forest floors, the distribution is dependent on the soil resources content and humidity (Tattersfield et al. 2001; Astor et al. 2014, 2015) and with the calcium content in the karsts landscape (Schilthuizen et al. 2001, 2003; Fon et al. 2017). Thus the distribution of the snails might vary with the leaf litters and soil quality as observed in the Western Ghats, India (Aravind et al. 2008, 2010) or other regions (Schmera \& Baur 2014; Nurinsiyah et al. 2016; Remm \& Lõhmus 2016). However, within a plant, the distribution of the snails depends on the resources available in the barks and the leaves, as observed for the snails $E$. amaliae (Watada \& Wada 1998). The snail E. amaliae graze on the surface of trunk and branch but did not graze on the leaves (Watada \& Wada 1998), which was also observed for the snail $K$. barrakporensis in the host plants. As argued in the spatial variation in abundance of animals (Brown et al. 1995), the encounter of the snail $K$. barrakporensis will be defined by the way the habitat conditions offer the available preferred niches across all the sampling spaces. Thus, variations in the morphology of the leaf and stem of the host plants offered varying niche requirements which may accounted for the varying relative abundances of the $K$. barrakporensis. Apart from the leaf and stem morphology, the composition of the associated biota including macroinvertebrates may appear important factor for the presence of the snail in the concerned habitat. Future exploration in 
these aspects is required to highlight the preferences of the plants by the snail in the background of the environmental variables like humidity, temperature and precipitation at the microhabitat levels. Nonetheless, the snail $K$. barrakporensis reflected generalist pattern of host plant association, similar to the succineid snails B. otosawarae and B. punctulispira (Sugiura et al. 2011) and E. amaliae (Watada \& Wada 1996, 1998) and S. jenynsi (Kasigwa 1999a,b).

Multiple features of the landscapes influence the spatial aggregation and orientation of the animals (Brown et al. 1995), which can be modelled using the Taylor's power law and various dispersion parameters (He \& Gaston 2003). At a smaller spatial extent, the count data to estimate distribution of organism are however, often over dispersed, which may be minimized through the use of the negative binomial model (NBD) (White \& Bennetts 1996). In the present instance, the extent of aggregation of $K$. barrakporensis in the lemon plant (C. limon) was assessed through several indicators, which suggested typical clumped distribution pattern. As reflected in the value of dispersion parameter, $k$, the compliance to the NBD was observed for the lemon plant, similar to the observations on the freshwater snail Oncomelania hupensis in freshwater habitats (Zhang et al. 2008). The clumped distribution is also observed for the citrus tree snail Drymaeus dormani (Bledose \& Minnick 1982), perhaps linked with the abundance of sooty mold, the food resource of the snail. Although the specific reasons are yet to be established, the aggregated dispersion pattern of $K$. barrakporensis may be attributed to the resource distribution and the availability of refuge in the lemon plants. Besides food resources, another probable factor that affects the distribution of the snails is dense canopy which provides shades and maintain high relative humidity condition as found in utilization of Ficus $s p$. by endangered arboreal snail S. (L.) eucosmia (Sugiura 2011; Takeuchi \& Takeda 2016). The dispersion in the host plants were also related to the height of the plant as observed for the E. amaliae (Watada \& Wada 1996) and S. jeynensi (Kasigwa 1999b). Perhaps, resource variations accounted for the differential distribution of $\mathrm{K}$. barrakporensis along the plant heights. Similar variations in vertical distribution in the plants are observed for the snails $S$. jenynsi (Kasigwa 1999a,b) and E. amaliae (Watada \& Wada 1996,1998), where the foliage pattern, temperature and the humidity were the factors determining the distribution in the trees.
Spatial distribution of a single species population is a powerful tool to explain the various types and causes of spatial distribution of animals (Brown et al. 1995; He \& Gaston 2003). Documentation of spatial distribution of species and its habitat characteristics is crucial for effective conservation and management (Margules \& Pressey 2000). Due to low dispersal ability and cryptic nature, land snails are good indicators of areas of conservation importance and endemicity (Moritz et al. 2001). While the concern for the land snails are raised for several reasons in India (Sen et al. 2012), still, species specific distribution and dispersion pattern are yet to be systematically deciphered. Studies on land snails in recent times are restricted mostly around the Western Ghats, India (Madhyastha et al. 2004; Aravind et al. 2005, 2008, 2010; Raheem et al. 2014), with emphasis on species documentation and diversity. Species specific preferences for the resources and habitat conditions are essential to supplement and strengthen the conservation effort of land snails. As a primary effort, the present observation is useful to understand host plant preferences and aggregation pattern of the micro land snail K. barrakporensis in natural condition. Similar initiatives on other species should be taken to make the conservation effort more effective and sustain the diversity of the land snails in India. In recent time, the snail K. barrakporensis is recorded as an invasive species associated with the coral tree Erythrina poeppigiana, in the hot houses of the 'Tropical Biome' of the Eden Project, Cornwall, UK (Preece and Naggs 2014). Therefore efforts for life history assessment and feeding and growth pattern of the snail K. barrakporensis should be initiated, particularly, to understand its prospective expansion beyond India.

\section{ACKNOWLEDGEMENT}

We thankfully acknowledge the helpful comments of two anonymous reviewers that enabled enhancement of the manuscript to its present state. We acknowledge the Head, Department of Zoology, University of Calcutta, Kolkata, India for the facilities provided in executing this research work, including DST-FIST and UGC-UPE II facilities. The Principal, Ramnagar College, Depal, Purba Medinipur, West Bengal, India is duly acknowledged for extending facilities in compilation of the paper works by the first author. 


\section{Author Contribution}

Both the authors contributed equally in conceiving the research work as well as data analysis (including statistical analysis) and compilation. The field collection was carried out by the first author solely.

\section{CONFLict OF InTEREST Statement}

As authors to this article we declare no conflict of interest.

\section{REFERENCES}

Addinsoft, S.A.R.L. (2010) XLSTAT software, Version 10.0, Paris, France.

Aguilera, A. M. and Escabias, M. (2000). Principal component logistic regression. Proceedings in Computational Statistics 2000, Physica-Verlag, pp. 175-180.

Anscombe, F.J. (1949) The statistical analysis of insect counts based on the negative binomial distribution. Biometrics, 5(2), 165-173.

Aravind, N.A., Rajashekhar, K.P., Madhyastha, N.A. (2008) Micromolluscs of Western Ghats, India: Diversity, distribution and threats. Zoosymposia, 1, 281-294.

Aravind, N.A., Rajashekhar, K.P., Madhyastha, N.A. (2010) A review of ecological studies on patterns and processes of distribution of land snails of the Western Ghats. Proceeding of World Congress of Malacology, 222p.

Aravind, N.A., Rajshekhar, K.P., Madhastha, N.A. (2005) Species diversity, endemism and distribution of land snails of the Western Ghats, India. Records of the Western Australian Museum, 68, 31-38.

Astor, T., Strengbom, J., Berg, M.P., Lenoir, L., Marteinsdóttir, B., Bengtsson, J. (2014) Underdispersion and overdispersion of traits in terrestrial snail communities on islands. Ecology and Evolution, 4(11), 20902102.

Astor, T., Lenoir, L., Berg, M.P. (2015) Measuring feeding traits of a range of litter-consuming terrestrial snails: leaf litter consumption, faeces production and scaling with body size. Oecologia, 178, 833-845.

Astor, T., von Proschwitz, T., Strengbon, J., Berg, M.P., Bengtsson, J. (2017) Importance of environmental and spatial components for species and trait composition in terrestrial snail communities. Journal of Biogeography, 44, 1362-1372.

Baur, B., Meier, T., Baur, A., Schmera, D. (2014) Terrestrial gastropod diversity in an alpine region: disentangling effects of elevation, area, geometric constraints habitat type and land use intensity. Ecography, 37, 390-401.

Blanford, W T and Godwin-Austen, H.H. (1908) Fauna of' British India, including Ceylon and Burma. Mollusca (Testacellidae and Zonitidae). Taylor and Francis, London. 303p.
Bledose, M.E., Minnick, D.R. (1982) Citrus tree snail and suppression of Citrus Microbiota. Environmental Entomology, 11, 1091-1095.

Blis C. I., Fisher, R.A. (1953) Fitting the negative binomial distribution to biological data. Biometrics, 9(2), $176-200$.

Bloch, C.P., Stock, M. (2014) Avoidance of canopy gaps by a common land snail, Caracolus caracolla (L.), in montane forest in Puerto Rico. Caribbean Naturalist, $8: 1-13$.

Brown, J.H., Mehlman, D.W., Stevens, G.C. (1995) Spatial variance in abundance. Ecology, 76(7): 2028-2043.

Craig, A.K. (1972) Observations on the arboreal snail $\mathrm{Or}$ thalicus floridensis. Quarternary Journal of the Florida Academy of Sciences, 35(1), 15-20.

Das, S., Bhaumik, S. (1998). Distribution and homing of tree snail Rhachisbengalensis Lamarck (Gastropoda) on a new host plant. The Journal of Bombay Natural History Society, 95, 142-142.

Durkan, T.H., Yeung, N.W., Meyer III, W.M., Hayes, K.A., Cowie, R.H. (2013) Evaluating the efficacy of land snail survey techniques in Hwaii: implications for conservation through the Pacific. Biodiversity and Conservation, 22, $3223-3232$.

Fox, J. (2008) Applied regression analysis and generalized linear models. Sage Publications, Inc., 688p.

Fon, J.K., Clements, G.R., Liew, T.-S. (2017) Diversity and biogeography of land snails (Mollusca: Gastropoda) in the lime stone kills of Perak, Peninsular Malaysia. Zookeys, 682, 1-94.

He, F., Gaston, K.J. (2003) Occupancy, spatial variance, and the abundance of species. American Naturalist, $162,366-375$.

Heatwole, H., Heatwole, A. (1978) Ecology of the Puerto Rican camaenid tree-snails. Malacologia, 17, 241315.

Kasigwa, P.F. (1999a) Dispersion factors in the arboreal snail Sitala jenynsi (Gastropoda: Ariophantidae). South African Journal of Zoology, 34 (4), 145-153.

Kasigwa, P.F. (1999b) Snail arboreality: the micro distribution of Sitala jenynsi (Gastropoda: Ariophantidae). South African Journal of Zoology, 34(4), 154-162.

Krebs, C.J. (1999) Ecological Methodology. Harper and Row. New York, 620p.

Lloyd, M. (1967) Mean crowding. Journal of Animal Ecology, 36, 1-30.

Ludwig, J.A., Reynolds, J.F. (1988) Statistical ecology: a primer on methods and computing. New York, USA: John Wiley \& Sons, 337p.

Lydeard, C., Cowie, R.H., Ponder, W.F., Bogan, A.E., Bouchet, P., Clark, S.A., Cummings, K.S., Frest, T.J., Gargominy, O., Herbert, D.G., Hershler, R., Perez, K.E., Roth, B., Seddon, M., Srong, E.E., Thompson, F.G. (2004) The global decline of nonmarine molluscs. BioScience, 54, 321-330. 
Madhyastha, N.A., Mavinkuruve, R.G., Shanbhag, S.P. (2004) Land snails of Western Ghats. In: Gupta, A.K., Kumarand, A., Ramakantha, V. (eds), ENVIS Bulletin: Wildlife and protected areas, conservation of rainforest in India. Wildlife Institute of India, Dehradun, India. 4, 143-151.

Margules, C.R., Pressey, R.L. (2000) Systematic conservation planning. Nature, 405, 243-253.

McCullagh, P., Nelder, J.A. (1989) Generalized linear models. Second Edition. Chapman and Hall, London, UK, 532p.

Mitra, S.C., Ramakrishna, Dey, A. (2004) Pictorial Handbook-Indian Land Snails (Selected Species), 344p. Director, Zoological Survey of India, Kolkata, India.

Moreno-Rueda, G. (2014) Distribution of arid-dwelling land snails according to dryness. Journal of Arid Environments, 103, 80-84.

Moritz, C., Richardson, K.S., Ferrier, S., Monteith, G.B., Stanisic, J., Williams, S.E., Whiffin, T. (2001) Biogeographical concordance and efficiency of taxon indicators for establishing conservation priority in a tropical rainforest biota. Proceedings of the Royal Society of London, B, 268, 1875-1881.

Nurinsiyah, A.S., Fauzia, H., Hennig, C., Hausdorf, B. (2016) Native and introduced land snail species as ecological indicators in different land use types in Java. Ecological Indicators, 70, 557-565.

Preece RC, Naggs F. (2014) Kaliella barrakporensis (Pfeiffer), a new hot-house alien in Britain. Journal of Conchology, 41, 781-782.

Raheem, D.C., Naggs, F., Preece, R.C., Mapatuna, Y., Kariyawasam, L., Eggleton, P. (2008) Structure and conservation of Sri Lankan land-snail assemblages in fragmented lowland rainforest and village home gardens. Journal of Applied Ecology, 45: 1019-1028.

Raheem, D.C., Taylor, H., Ablett, J., Preece, R.C., Aravind, N.A., Naggs, F. (2014) A Systematic Revision of the land snails of the Western Ghats of India. Tropical Natural History, 4: 1-294.

Rao, H.S. (1925) On certain succineid molluscs from the Western Ghats, Bombay Presidency Records of the Indian Museum, 27: 385-400.

Raut SK, Biswas A. (1991) Natural History of the tree snail Rhachis bengalensis Lamarck (Gastropoda: Enidae). Bulletin of Malacology, R.O.C., 16, 78-80.

Raut, S.K., Ghose, K.C. (1984) Natural History of a Succineid snail, Indosuccenia semiserica (Gould). Bulletin of Zoological Survey of India, 5(2\&3), 191-193.

Remm, L., Lõhmus, A. (2016) Semi-naturally managed forests support diverse land snail assemblages in Estonia. Forest Ecology and Management, 363, 159-168.
Rosenberg, G. (2014) A new critical estimate of named species-level diversity of the recent Mollusca. American Malacological Bulletin, 32(2), 308-322.

Sasaki, T. (2008) Micromolluscs in Japan: Taxonomic composition, habitats, and future topics. Zoosymposia, $1,147-232$.

Schilthuizen, M., Rutjes, H.A. (2001) Land snail diversity in a square kilometre of tropical rainforest in Sabah, Malaysian Borneo. Journal of Molluscan Studies, 67(4), 417-423.

Schilthuizen, M., Chai, H.N., Kimsen, T.E., Vermeulen, J.J. (2003) Abundance and diversity of land snails (Mollusca: Gastropoda) on limestone hills in Borneo. The Raffles Bulletin of Zoology, 51, 35-42.

Schmera, D., Baur, B. (2014) Gastropod communities in alpine grassland are characterized by high beta diversity. Community Ecology, 15(2), 246-255.

Solen, D.H., Croft, B.A. (1998) Detecting differences in arthropod aggregation by comparing the proportion of occupied sample units. Entomologia Experimentalis et Applicata, 87, 59-66.

Sugiura, S. (2011) Diverse plant taxa used by arboreal succineid snails as microhabitats. Journal of Natural History, 45, 23-24.

Takeuchi, M., Takeda, Y. (2016) Dependence of the endangered arboreal snail Satsuma (Luchuhadra) eucosmia eucosmia (Camaenidae) on Ficus (Moraceae) trees as its main habitat. Molluscan Research, 36(4), 231-238.

Tattersfied, P., Warui, C.M., Seddon, M.B., Kiringe, J.W. (2001) Land snail faunas of afromontane forests of Mount Kenya, Kenya: Ecology, diversity and distribution pattern. Journal of Biogeography, 28(7), 843861.

Taylor, L.R. (1961) Aggregation, variance and the mean. Nature, 189, 732-735.

Watada, H., Wada, K. (1996) Arboreal distribution of the land snail Euhadra amaliae. Venus, 55, 123-137.

Watada, H., Wada, K. (1998) Tree species preference of the arboreal snail Euhadra amaliae. Venus, 57, 29-37.

White, G.C., Bennetts, R.E. (1996) Analysis of frequency count data using the negative binomial distribution. Ecology, 77, 2549-2557.

Zar, J.H. (1999) Biostatistical Analysis. IV ed. New Delhi, India: Pearson Education Singapore Pte. Ltd., Indian Branch, 663p.

Zhang, Z.J., Ong, S. H., Lynn, H. S., Peng, W. X., Zhou, Y. B., Zhao, G. M., Jiang, Q. W. (2008) Generalized negative binomial distribution: a promising statistical distribution for Oncomelania hupensis in the lakeand marsh-land regions of China. Annals of Tropical Medicine and Parasitology, 102(6), 541 -552. 